\title{
PENGARUH PEMBERIAN PUPUK HAYATI DAN KONSENTRASI PUPUK PELENGKAP ALKALIS TERHADAP POPULASI DAN BIOMASSA CACING TANAH PADA PERTANAMAN BAWANG MERAH (Allium ascalonicum L.) DI GEDONG MENENG
}

\author{
Devita Ayuningrum, Sri Yusnaini, Rianida Taisa dan Kushendarto \\ Jurusan Agroteknologi, Fakultas Pertanian, Universitas Lampung \\ J1. Prof. Dr. Soemantri Brojonegoro, No. 1 Bandar Lampung 35145 \\ Email: devitaayuningrum@gmail.com
}

\begin{abstract}
ABSTRAK
Penelitian ini bertujuan untuk mengetahui pengaruh pemberian pupuk hayati (Bio max grow), pupuk pelengkap (Plant catalyst) dan interaksi antara pupuk hayati (Bio max grow) dan pupuk pelengkap (Plant catalyst) terhadap peningkatan populasi dan biomassa cacing tanah pada pertanaman bawang merah (Allium ascalonicum L.). Penelitian ini dilaksanakan di Laboratorium Lapang Terpadu, Fakultas Pertanian, Universitas lampung pada Juli - Oktober 2017. Penelitian ini menggunakan Rancangan Acak Kelompok (RAK) yang disusun secara faktorial. Faktor pertama dosis pupuk hayati (Bio max grow) dan faktor kedua kosentrasi pupuk pelengkap (Plant catalyst). Setiap perlakuan diulang sebanyak tiga kali sehingga diperoleh 24 petak satuan percobaan. Data yang diperoleh dihomogenkan ragamnya menggunakan Uji Barlett dan kemenambahan data diuji dengan Uji Tukey. Setelah asumsi terpenuhi data diolah dengan analisis ragam pada taraf $5 \%$ dan diuji lanjut dengan Uji Beda Nyata terkecil pada taraf 5\%. Kemudian dilakukan Uji Korelasi untuk mengetahui hubungan antara variabel pendukung dengan variabel utama. Hasil penelitian menunjukan bahwa: 1). Pemberian pupuk hayati (Bio max grow) dengan dosis $10 \mathrm{ml}$ $\mathrm{L}^{-1}$ mampu meningkatkan populasi dan biomassa cacing tanah di kedalaman $0-10 \mathrm{~cm}$ dan $10-20 \mathrm{~cm}$. (2). Pemberian pupuk pelengkap (Plant catalyst) mampu meningkatkan populasi cacing tanah di kedalaman $0-10,10-20$, dan $20-30 \mathrm{~cm}$ dan biomassa cacing tanah di kedalaman $0-10$ dan $10-20 \mathrm{~cm}$ pada umur 86 HST.(3). Terdapat interaksi antara pupuk hayati dan Pupuk Pelengkap terhadap populasi dan biomassa cacing tanah di kedalaman $0-10 \mathrm{~cm}, 10-20 \mathrm{~cm}$ dan $20-30 \mathrm{~cm}$. Tanpa pemberian pupuk hayati, pupuk pelengkap dengan konsentrasi $0,0,5,1$, dan 1,5 $\mathrm{g} \mathrm{L}^{-1}$ dapat meningkatkan populasi cacing tanah, sedangkan pada pemberian pupuk hayati $10 \mathrm{ml} \mathrm{L}^{-1}$, pupuk pelengkap dengan konsentrasi $1 \mathrm{~g} \mathrm{~L}^{-1}$ menghasilkan populasi dan biomassa cacing tanah lebih tinggi dibandingkan konsentrasi pupuk pelengkap lainnya pada umur 86 HST.
\end{abstract}

Kata Kunci : Bawang merah, pupuk pelengkap, pupuk hayati, tanah ultisol, cacing tanah.

\section{PENDAHULUAN}

Bawang merah (Allium ascalonicum L.) atau yang sering disebut Brambang dalam bahasa (Jawa) adalah nama tanaman dari familia Alliaceae. Umbi tanaman bawang merah merupakan bahan utama untuk bumbu dasar masakan Indonesia. Bawang merah memiliki nilai ekonomi yang tinggi karena hampir semua kalangan membutuhkan tanaman ini sebagai bahan tambahan obat tradisional dan penyedap rasa. Tanaman bawang merah dapat memberikan produksi yang tinggi apabila diikuti dengan penerapan teknologi yang memadai, yaitu teknologi yang diterapkan sesuai dengan sifat komoditas itu sendiri maupun kondisi agroekosistem dimana komoditas tersebut ditanam. Menghasilkan produksi bawang merah (Allium ascalonicum L.) yang baik dengan hasil maksimal dalam penelitian ini menggunakan jenis pupuk pelengkap dan pupuk hayati. Pupuk pelengkap yang digunakan yaitu pupuk pelengkap Plant Catalyst. Plant Catalyst 2006 adalah Pupuk Pelengkap Cair (PPC) yang diformulasikan dengan kandungan unsur hara yang lengkap, baik unsur hara makro maupun mikro (PT. Centranusa Insan Cemerlang, 2001).

Plant Catalyst 2006 berfungsi meningkatkan kemampuan tanaman menyerap unsur unsur hara dari berbagai pupuk utama, seperti Urea, TSP, Kcl, ZA, maupun pupuk alami, seperti pupuk kandang, kompos dan lain lain oleh tanaman sehingga berproduksi tinggi. Adanya kandungan unsur hara mikro $\mathrm{Fe}, \mathrm{Mn}, \mathrm{Cl}, \mathrm{Cu}$, $\mathrm{Zn}, \mathrm{B}$ dan Mo berfungsi untuk mengatasi kekurangan unsur hara mikro dalam tanah yang terus menerus diserap tanaman, ataupun yang ketersediaannya di dalam tanah sangat rendah dengan terpenuhinya kebutuhan 
unsur hara tanaman secara lengkap, maka tanaman akan tumbuh sehat dan memberikan hasil yang maksimal (Tim Plant Catalyst, 2006). Pupuk hayati yang digunakan yaitu Bio Max Grow (BMG) dengan menggunakan teknologi AGPI (Agriculture Growth Promoting Inoculant) adalah inokulan campuran yang berbentuk cair, mengandung hormon tumbuh dan berbahan aktif bakteri penambat $\mathrm{N}_{2}$ secara asosiatif, mikroba pelarut fosfat dan penghasil selulose dan pemberian pupuk hayati dapat memberikan beberapa keuntungan seperti struktur tanah yang lebih baik untuk pertumbuhan tanaman, meningkatkan hara tersedia bagi tanaman dan meningkatkan populasi dan aktivitas mikroba di dalam tanah (Rao, 1994).

Salah satu biota tanah yang memiliki peranan penting sebagai indikator kesuburan tanah adalah cacing tanah (Buck dkk.,1999), dikarenakan cacing tanah mempunyai peranan penting terhadap perbaikan sifat tanah, diantaranya menghancurkan bahan organik, membentuk kemantapan agregat antara bahan organik dan bahan mineral tanah, memperbaiki struktur tanah dalam perbaikan kesuburan tanah dengan menghancurkan secara fisik, dan dapat memecahan bahan organik menjadi humus (Barnes dan Granval, 1997). Suin (1982), menyatakan bahwa tanah dengan kepadatan populasi cacing tanahnya tinggi akan menjadi subur, sebab kotoran cacing tanah yang bercampur dengan tanah merupakan pupuk yang kaya akan nitrat organik, posfat, dan kalium, yang membuat tanaman mudah menerima pupuk yang diberikan ke tanah, disamping formasi bahan organik tanah dan mendistribusikan kembali bahan organik di dalam tanah.

Penelitian ini bertujuan (1). Untuk mengetahui pengaruh pemberian pupuk hayati (Bio max grow) terhadap populasi dan biomassa cacing tanah pada pertanaman bawang merah (Allium ascalonicum L.), (2). Untuk mengetahui pengaruh pemberian pupuk pelengkap (Plant catalyst) terhadap populasi dan biomassa cacing tanah pada pertanaman bawang merah (Allium ascalonicum L.), dan (3). Untuk mengetahui interaksi antara pupuk hayati (Bio max grow) dan pupuk pelengkap (Plant catalyst) terhadap peningkatan populasi dan biomassa cacing tanah pada pertanaman bawang merah (Allium ascalonicum L.).

\section{METODE PENELITIAN}

Penelitian ini dilaksanakan di Laboratorium Lapang Terpadu Fakultas Pertanian Universitas lampung pada Juli - Oktober 2017. Analisis tanah dan cacing tanah dilakukan di Laboratorium Ilmu Tanah, Fakultas Pertanian, Universitas Lampung.Bahan-bahan yang digunakan dalam penelitian ini yaitu sampel tanah, benih bawang merah varietas bima brebes, pupuk hayati (bio max grow), pupuk pelengkap (plant catalyst), alkohol $70 \%$, NPK, KCL, dethine, pupuk kandang kambing, sedangkan alat-alat yang digunakan dalam penelitian ini adalah mikroskop, sekop, cangkul, meteran, karung, kertas label, plastik, botol plastik, tali rafia, patok kayu $25 \mathrm{~cm}$ x $25 \mathrm{~cm}$, tissu, spidol, timbangan cacing, termometer tanah, oven, mikroskop, cawan petri, pinset, dan botol film. Penelitian ini dilaksanakan dengan menggunakan Rancangan Acak Kelompok (RAK) yang disusun secara faktorial. Faktor pertama dosis pupuk hayati bio max grow $(\mathrm{H})$ dan faktor kedua kosentrasi pupuk pelengkap plant catalyst $(\mathrm{P})$. Faktor pertama terdiri dari dua taraf yaitu $\mathrm{H}_{0}=$ tanpa pupuk (Bio Max Grow) dan $\mathrm{H}_{1}=$ menggunakan pupuk (Bio Max Grow). Faktor kedua terdiri dari empat taraf yaitu $\mathrm{P}_{0}=\tan p \mathrm{a}$ pupuk pelengkap, $\mathrm{P}_{1}=0,5 \mathrm{~g} \mathrm{~L}^{-1}, \mathrm{P}_{2}=1 \mathrm{~g} \mathrm{~L}^{-1}, \mathrm{P}_{3}=1,5 \mathrm{~g}$ $\mathrm{L}^{-1}$. Setiap perlakuan diulang sebanyak tiga kali sehingga diperoleh 24 petak satuan percobaan. Data yang diperoleh dihomogenkan ragamnya dengan Uji Barlett dan kemenambahan data diuji dengan Uji Tukey. Setelah asumsi terpenuhi data diolah dengan analisis ragam pada taraf nyata 5\% dan diuji lanjut dengan uji beda nyata terkecil (BNT) pada taraf 5\%. Kemudian dilakukan Uji Korelasi untuk mengetahui hubungan antara variabel pendukung dengan variabel utama.

\section{Variabel Utama}

Jumlah Populasi cacing tanah ( ekor $\mathbf{m}^{-2}$ ) . Perhitungan jumlah populasi cacing tanah dengan menggunakan tangan (hand sorting) dengan cara menggali tanah ukuran $25 \mathrm{~cm} \times 25 \mathrm{~cm}$ dengan kedalaman 0 - $10 \mathrm{~cm}, 10-20 \mathrm{~cm}$ dan $20-30 \mathrm{~cm}$ untuk memisahkan cacing dari tanah satu persatu untuk dihitung jumlah cacing tanah disetiap petak percobaan yang dilakukan sebelum tanam, saat fase vegetatif ( 32 HST), dan waktu saat panen (86 HST).

Biomassa cacing tanah $\left(\mathrm{g} \mathrm{m}^{-2}\right)$. Setelah dilakukan metode handsorting dengan cara memisahkan cacing satu persatu di kedalaman berbedabeda, lalu cacing dihitung bobotnya dengan menggunakan timbangan cacing tanah sehingga didapatkan biomassa cacing tanah di setiap petak percobaan dan disetiap kedalaman tanah $0-10 \mathrm{~cm}, 10$ $-20 \mathrm{~cm}, 20-30 \mathrm{~cm}$ yang dilakukan sebelum tanam, saat fase vegetatif (32HST) dan panen (86 HST).

\section{Variabel Pendukung}

Variabel pendukung yang diamati yaitu kadar air tanah sebelum perlakuan dan setelah perlakuan, $\mathrm{pH}$ tanah sebelum perlakuan dan setelah perlakuan, suhu 
tanah $\left({ }^{\circ} \mathrm{C}\right)$ sebelum perlakuan dan setelah perlakuan, c - organik sebelum perlakuan dan setelah perlakuan, dan menghitung hasil produksi dari jumlah umbi dan bobot umbi setelah panen.

\section{HASIL DAN PEMBAHASAN}

Hasil analisis ragam pada Tabel 1 , menunjukan di kedalaman $0-10 \mathrm{~cm}$, perlakuan pupuk hayati, pupuk pelengkap dan interaksi berpengaruh nyata terhadap populasi dan biomassa cacing tanah pada umur $86 \mathrm{HST}$. Hasil uji lanjut BNT 5\% (Tabel 2), menunjukan adanya interaksi pupuk hayati dan konsentrasi pupuk pelengkap terhadap populasi cacing tanah di kedalaman $0-10 \mathrm{~cm}$ pada umur 86 HST. Pada perlakuan tanpa pupuk hayati $\left(\mathrm{H}_{0}\right)$, pupuk pelengkap dengan konsentrasi $0,5 \mathrm{~g} \mathrm{~L}^{-1}\left(\mathrm{P}_{1}\right)$ dan $1,5 \mathrm{~g} \mathrm{~L}^{-1}\left(\mathrm{P}_{3}\right)$ menghasilkan populasi cacing tanah yang tidak berbeda dan lebih tinggi dibandingkan pupuk pelengkap dengan konsentrasi $0 \mathrm{~g} \mathrm{~L}^{-1}\left(\mathrm{P}_{0}\right)$ dan $1 \mathrm{~g} \mathrm{~L}^{-1}$ $\left(\mathrm{P}_{2}\right)$. Pada pemberian pupuk hayati $10 \mathrm{ml} \mathrm{L}^{-1}\left(\mathrm{H}_{1}\right)$, pupuk pelengkap $0 \mathrm{~g} \mathrm{~L}^{-1}\left(\mathrm{P}_{0}\right), 0,5 \mathrm{~g} \mathrm{~L}^{-1}\left(\mathrm{P}_{1}\right), 1 \mathrm{~g} \mathrm{~L}^{-1}\left(\mathrm{P}_{2}\right)$ dan $1,5 \mathrm{~g} \mathrm{~L}^{-1}\left(\mathrm{P}_{3}\right)$ menghasilkan popuasi cacing tanah yang tidak berbeda. Pupuk pelengkap dengan konsentrasi 0,5 $\mathrm{g} \mathrm{L}^{-1}\left(\mathrm{P}_{1}\right)$ dan $1,5 \mathrm{~g} \mathrm{~L}^{-1}\left(\mathrm{P}_{3}\right)$ menghasilkan populasi cacing tanah tidak berbeda pada perlakuan tanpa pupuk hayati dan diberi pupuk hayati $10 \mathrm{ml} \mathrm{L}^{-1}$ tetapi, pupuk pelengkap dengan konsentrasi $0 \mathrm{~g} \mathrm{~L}^{-1}\left(\mathrm{P}_{0}\right)$ dan $1 \mathrm{~g} \mathrm{~L}^{-1}\left(\mathrm{P}_{2}\right)$ menghasilkan populasi cacing tanah yang berbeda dan lebih tinggi diberi pupuk hayati $10 \mathrm{ml} \mathrm{L}^{-1}$.
Hasil Uji lanjut BNT 5\% (Tabel 3), menunjukan adanya interaksi pupuk hayati dan konsentrasi pupuk pelengkap terhadap biomassa cacing tanah di kedalaman 0 - $10 \mathrm{~cm}$ pada umur 86 HST. Pada perlakuan tanpa pupuk hayati $\left(\mathrm{H}_{0}\right)$, pupuk pelengkap dengan konsentrasi $0,5 \mathrm{~g} \mathrm{~L}^{-1}\left(\mathrm{P}_{1}\right)$ dan $1 \mathrm{~g} \mathrm{~L}^{-1}\left(\mathrm{P}_{2}\right)$ menghasilkan biomassa cacing tanah tidak berbeda dan berbeda dengan konsentrasi $1,5 \mathrm{~g} \mathrm{~L}^{-1}\left(\mathrm{P}_{3}\right)$ dan $0 \mathrm{~g} \mathrm{~L}^{-1}\left(\mathrm{P}_{0}\right)$. Pada pemberian pupuk hayati $10 \mathrm{ml} \mathrm{L}^{-1}\left(\mathrm{H}_{1}\right)$, pupuk pelengkap $1 \mathrm{~g} \mathrm{~L}^{-1}\left(\mathrm{P}_{2}\right)$ menghasilkan biomassa cacing tanah tetinggi dibandingkan pupuk pelengkap dengan konsentrasi $0 \mathrm{~g}$ $\mathrm{L}^{-1}\left(\mathrm{P}_{0}\right), 0,5 \mathrm{~g} \mathrm{~L}^{-1}\left(\mathrm{P}_{1}\right)$, dan 1,5 $\mathrm{g} \mathrm{L}^{-1}\left(\mathrm{P}_{3}\right)$. Pupuk pelengkap dengan konsentrasi $0,5 \mathrm{~g} \mathrm{~L}^{-1}\left(\mathrm{P}_{1}\right)$ dan $1,5 \mathrm{~g} \mathrm{~L}^{-}$ ${ }^{1}\left(\mathrm{P}_{3}\right)$ menghasilkan biomassa cacing tanah tidak berbeda pada perlakuan tanpa pupuk hayati dan diberi pupuk hayati $10 \mathrm{ml} \mathrm{L}^{-1}$ tetapi, pupuk pelengkap dengan konsentrasi $0 \mathrm{~g} \mathrm{~L}^{-1}\left(\mathrm{P}_{0}\right)$ dan $1 \mathrm{~g} \mathrm{~L}^{-1}\left(\mathrm{P}_{2}\right)$ menghasilkan populasi cacing tanah yang berbeda dan lebih tinggi diberi pupuk hayati $10 \mathrm{ml} \mathrm{L}^{-1}$.Hasil Uji korelasi (Tabel 4), menunjukan bahwa sifat kimia tanah seperti $\mathrm{pH}$ tanah memiliki korelasi nyata positif dengan populasi cacing, biomassa cacing tanah, dan bobot umbi bawang merah, C- organik tanah memiliki korelasi nyata dengan populasi cacing dan biomassa cacing tanah, kadar air tanah memiliki korelasi nyata positif dengan populasi cacing tanah, dan suhu tanah memiliki korelasi nyata positif dengan biomassa cacing tanah.

Pada umur 32 HST pemberian pupuk hayati 10 $\mathrm{ml} \mathrm{L}-1$ memberikan pengaruh nyata terhadap populasi

Tabel 1. Hasil analisis ragam pengaruh pemberian pupuk hayati dan konsentrasi pupuk pelengkap alkalis terhadap populasi dan biomassa cacing tanah pada umur 86 HST.

\begin{tabular}{|c|c|c|}
\hline \multirow[t]{2}{*}{ Sumber Keragaman } & \multicolumn{2}{|c|}{ F-hitung dan Signifikansi } \\
\hline & Populasi Cacing Tanah & Biomassa Cacing Tanah \\
\hline & \multicolumn{2}{|c|}{ Kedalaman $0-10 \mathrm{~cm}$} \\
\hline Hayati $(\mathrm{H})$ & $47,23 *$ & $5,58 *$ \\
\hline Pelengkap (P) & $14,75^{*}$ & $12,41 *$ \\
\hline H X P & $8,25^{*}$ & $6,12 *$ \\
\hline
\end{tabular}

Tabel 2. Pengaruh interaksi antara pemberian pupuk hayati dan konsentrasi pupuk pelengkap alkalis terhadap populasi cacing tanah di kedalaman $0-10 \mathrm{~cm} 86$ HST pada pertanaman bawang merah (Allium ascalonicum L.).

\begin{tabular}{ccccc}
\hline \multirow{2}{*}{ Perlakuan } & \multicolumn{4}{c}{ Populasi Cacing Tanah } \\
\cline { 2 - 5 } & $\mathrm{P}_{0}=0 \mathrm{~g} \mathrm{~L}^{-1}$ & $\mathrm{P}_{1}=0,5 \mathrm{~g} \mathrm{~L}^{-1}$ & $\mathrm{P}_{2}=1 \mathrm{~g} \mathrm{~L}^{-1}$ & $\mathrm{P}_{3}=1,5 \mathrm{~g} \mathrm{~L}^{-1}$ \\
\hline Tanpa pupuk & & $\ldots \ldots .\left(\right.$ ekor m$\left.^{-2}\right) \ldots \ldots$ & \\
$\left(\mathrm{H}_{0}\right)$ & $53(4) \mathrm{B}$ & $96(5) \mathrm{A}$ & $85(4) \mathrm{B}$ & $112(5) \mathrm{A}$ \\
Diberi pupuk & $\mathrm{b}$ & $\mathrm{a}$ & $\mathrm{b}$ & $\mathrm{a}$ \\
$10 \mathrm{ml} \mathrm{L}^{-1}\left(\mathrm{H}_{1}\right)$ & $101(5) \mathrm{A}$ & $123(5) \mathrm{A}$ & $160(5) \mathrm{A}$ & $112(5) \mathrm{A}$ \\
\hline BNT $5 \%$ & $\mathrm{a}$ & $\mathrm{a}$ & $\mathrm{a}$ & $\mathrm{a}$ \\
\hline
\end{tabular}

Keterangan :Angka yang diikuti oleh huruf yang sama menunjukan tidak berbeda nyata dengan uji BNT pada taraf 5\%. Huruf kecil dibaca horizontal dan huruf besar dibaca vertikal. Angka - angka dalam kurung merupakan data hasil tranformasi $(\sqrt{x})$. 
Tabel 3. Pengaruh interaksi antara pemberian pupuk hayati dan konsentrasi pupuk pelengkap alkalis terhadap biomassa cacing di kedalaman $0-10 \mathrm{~cm}$ pada pertanaman bawang merah (Allium ascalonicum L.) pada umur 86 HST.

\begin{tabular}{|c|c|c|c|c|}
\hline \multirow{2}{*}{ Perlakuan } & \multicolumn{4}{|c|}{ Biomassa Cacing Tanah } \\
\hline & $\mathrm{P}_{0}=0 \mathrm{~g} \mathrm{~L}^{-1}$ & $\mathrm{P}_{1}=0,5 \mathrm{~g} \mathrm{~L}^{-1}$ & $\mathrm{P}_{2}=1 \mathrm{~g} \mathrm{~L}^{-1}$ & $\mathrm{P}_{3}=1,5 \mathrm{~g} \mathrm{~L}^{-1}$ \\
\hline \multicolumn{5}{|c|}{$\ldots\left(\mathrm{g} \mathrm{m}^{-2}\right) \ldots \ldots$} \\
\hline Tanpa pupuk & $2,67(1,32) \mathrm{B}$ & $29,33(2,31) \mathrm{A}$ & $15,63(1,90) \mathrm{B}$ & $11,15(1,78) \mathrm{A}$ \\
\hline$\left(\mathrm{H}_{0}\right)$ & $\mathrm{c}$ & $\mathrm{a}$ & a & $\mathrm{b}$ \\
\hline Diberi pupuk & $10,03(1,77) \mathrm{A}$ & $20(1,96) \mathrm{A}$ & $36,05(2,54) \mathrm{A}$ & $13,14(1,87) \mathrm{A}$ \\
\hline $10 \mathrm{ml} \mathrm{L}^{1}\left(\mathrm{H}_{1}\right)$ & $b$ & $\mathrm{~b}$ & $\mathrm{a}$ & $\mathrm{b}$ \\
\hline BNT $5 \%$ & & 0,38 & & \\
\hline
\end{tabular}

Tabel 4. Uji korelasi sifat kimia tanah dengan populasi cacing, biomassa cacing, jumlah umbi dan bobot umbi pada tanaman bawang merah (Allium ascalonicum L.).

\begin{tabular}{lcccc}
\hline \multirow{2}{*}{ Koefisien Korelasi (r) } & \multicolumn{4}{c}{ Koefisien Korelasi (r) } \\
\cline { 2 - 5 } & $\begin{array}{c}\text { Populasi Cacing } \\
\left(\text { ekor m}^{-2}\right)\end{array}$ & $\begin{array}{c}\text { Biomassa Cacing } \\
\left(\mathrm{g} \mathrm{m}^{-2}\right)\end{array}$ & $\begin{array}{c}\text { Jumlah Umbi } \\
(\text { umbi })\end{array}$ & $\begin{array}{c}\text { Bobot Umbi } \\
(\mathrm{g})\end{array}$ \\
\hline $\mathrm{pH}$ & $0,62^{*}$ & $0,42^{*}$ & $0,08^{\text {tn }}$ & $0,43^{*}$ \\
C- organik (\%) & $0,67^{*}$ & $0,69^{*}$ & $0,08^{\text {tn }}$ & $0,40^{\text {tn }}$ \\
Kadar air (\%) & $0,41^{*}$ & $0,13^{\text {tn }}$ & $0,02^{\text {tn }}$ & $0,26^{\text {tn }}$ \\
Suhu $\quad\left({ }^{\circ}\right.$ C) & $0,24^{\text {tn }}$ & $0,48^{*}$ & $0,04^{\text {tn }}$ & $0,18^{\text {tn }}$ \\
\hline
\end{tabular}

Keterangan : ${ }^{\text {th }}=$ tidak berbeda nyata pada taraf $5 \%$

$*=$ berbeda nyata pada taraf $5 \%$

cacing tanah di kedalaman $0-10$ dan $10-20 \mathrm{~cm}$ dan biomassa cacing tanah di kedalaman $10-20 \mathrm{~cm}$. Sedangkan pada umur 86 HST pupuk hayati berpengaruh nyata terhadap populasi dan biomassa cacing tanah di kedalaman $0-10$ dan $10-20 \mathrm{~cm}$. Hal ini diduga pupuk hayati mengandung berbagai macam mikroba diantaranya Azospirillum sp., Azotobacter sp., Lactobacillus sp., Mikroba pelarut fosfat, Mikroba selulolitik, Pseudomonas sp., Hormon indole acetic acid, Enzim alkaline fostase, dan Enzim acid fostase yang mampu menguraikan bahan - bahan organik yang masih segar dan mengubahnya dalam bentuk selulose dan hemiselulose yang selanjutkan akan dimakan oleh cacing tanah dan dikeluarkan dalam bentuk kascing yang baik untuk kesuburan tanah sehingga mampu meningkatkan aktivitas mikro maupun makro organisme di dalam tanah. (Rao, 1994).

Namun, pada umur 32 HST dan 86 HST pemberian pupuk hayati tidak berpengaruh nyata di kedalaman $20-30 \mathrm{~cm}$. Hal ini diduga sifat kimia tanah seperti $\mathrm{pH}$ tanah yang ada di kedalaman tersebut bersifat asam sehingga cacing tanah sukar hidup di kedalaman tersebut, suhu tanah juga sangat berpengaruh terhadap populasi cacing tanah. Hal ini diduga tutupan vegetasi yang rapat akan menghalangi cahaya matahari secara langsung menembus tanah yang pada akhirnya akan mempengaruhi suhu tanah. Menurut Waluyo (1993), suhu optimum yang dapat membantu pertumbuhan cacing dan penetasan kokon berkisar antara suhu 15 $25{ }^{\circ} \mathrm{C}$, cacing dewasa dapat berkembang biak berkisar pada suhu $28-32{ }^{\circ} \mathrm{C}$ dan suhu optimal yaitu $28{ }^{\circ} \mathrm{C}$, selain itu kadar air tanah juga sangat berpengaruh dengan populasi cacing tanah dikarenakan cacing tanah sangat membutuhkan air dalam melangsungkan hidupnya serta bahan organik di kedalaman tersebut sudah menipis. Menurut Buckman dan Brady (1982), menyatakan bahwa bahan organik tanah sangat besar pengaruhnya terhadap perkembangan populasi cacing tanah, karena bahan organik yang terdapat didalam tanah sangat diperlukan oleh cacing tanah untuk melangsungkan kehidupannya sehingga bobot biomassa cacing tanah pun ikut meningkat.Selain itu, pemberian pupuk hayati (Bio max grow) dapat memberikan manfaat seperti menyehatkan tanah dan tanaman, dengan melalui perbaikan struktur dan tekstur tanah yang telah mengalami kerusakan karena pemakaian pupuk kimia yang secara terus menerus dan berlebihan, merangsang pertumbuhan akar tanaman sehingga jangkauan akar mengambil zat (Unsur hara) yang diperlukan meningkat, menetralisir, mengurai dan merombak faktor penghambat, sehingga terjadi keseimbangan yang menjamin ketersediaan unsur hara atau zat yang dibutuhkan oleh tanaman. 
Pemberian pupuk pelengkap dengan menghasilkan populasi dan biomassa cacing tanah tertinggi yaitu dengan konsentrasi $1 \mathrm{~g} \mathrm{~L}^{-1}\left(\mathrm{P}_{2}\right)$ yang dapat menghasilkan nilai tertinggi untuk variabel pengamatan populasi dan biomassa cacing tanah di kedalaman 0 $10 \mathrm{~cm}, 10-20 \mathrm{~cm}$, dan $20-30 \mathrm{~cm}$ pada umur 86 HST. Hal ini diduga pupuk pelengkap memiliki sifat alkaline (basa) yang dapat meningkatkan $\mathrm{pH}$ tanah sehingga semakin naik $\mathrm{pH}$ di dalam tanah maka akan mempengaruhi aktivitas cacing tanah yang semakin baik. Namun, apabila pupuk pelengkap yang diberikan dengan konsentrasi 1,5 $\mathrm{g} \mathrm{L}^{-1}\left(\mathrm{P}_{3}\right)$ ke dalam tanah maka akan menurunkan populasi cacing tanah. Hal ini diduga pupuk pelengkap mengandung unsur hara makro; $\mathrm{N}, \mathrm{P}, \mathrm{K}, \mathrm{Mg}$, $\mathrm{Ca}$, dan $\mathrm{S}$ dan unsur hara mikro; $\mathrm{Fe}, \mathrm{Mn}, \mathrm{Cu}, \mathrm{Zn}, \mathrm{Bo}$, dan Mo yang apabila diberikan jumlahnya terlalu banyak kedalam tanah maka dapat bersifat racun.

Menurut Siddique (2005), pertambahan bobot atau biomassa cacing tanah merupakan indikasi dari pertumbuhan populasi cacing tanah yang baik karena mendapatkan nutrisi yang cukup dari bahan organik yang diberikan di dalam tanah serta kondisi yang sesuai dengan pertumbuhan cacing tanah namun jika bobot cacing tanah rendah menandakan kurangnya nutrisi yang diberikan di dalam tanah dan mencerminkan kondisi yang kurang sesuai di lingkungannya.Interaksi pupuk hayati dan pupuk pelengkap terhadap populasi dan biomassa cacing tanah tertinggi yaitu pada pemberian pupuk hayati $10 \mathrm{ml} \mathrm{L}^{-1}$ dan pupuk pelengkap $1 \mathrm{~g} \mathrm{~L}^{-1}\left(\mathrm{P}_{1}\right)$ di kedalaman $0-10$ $\mathrm{cm}, 10-20 \mathrm{~cm}$, dan $20-30 \mathrm{~cm}$ dan biomassa cacing tanah tertinggi di kedalaman $0-10 \mathrm{~cm}$ dan $20-30 \mathrm{~cm}$. Hal ini diduga pupuk hayati dapat meningkatkan aktivitas mikroorganisme didalam tanah yang mampu mempebaiki sifat fisika, kimia dan biologi di dalam tanah serta kandungan di dalam pupuk pelengkap juga memiliki unsur hara yang lengkap seperti unsur - unsur hara makro dan mikro yang dapat memperbaiki kesuburan tanah sehingga populasi dan biomassa cacing tanah pun ikut meningkat.

Menurut Suin (1982), tanah dengan kepadatan populasi dan biomassa cacing tanah yang tinggi akan menjadi subur, sebab kotoran cacing tanah yang bercampur dengan tanah merupakan pupuk yang kaya akan nitrat organik, posfat, dan kalium, yang membuat tanaman tumbuh lebih baik dan optimal. Menurut PT. Centranusa Insan Cemerlang (2001), pemberian pupuk pelengkap dengan sesuai anjuran dapat mempengaruhi beberapa sifat kimia tanah yakni terdapat unsur hara Copper $(\mathrm{Cu})$ sangat dibutuhkan pada tanah organik, tanah pasir dan tanah masam, komposisi di dalam pupuk pelengkap juga tidak merusak struktur tanah sehingga cacing tanah masih dapat menyesuaikan diri pada kondisi lingkungannya serta pupuk pelengkap juga memiliki sifat alkali atau bassa yang dapat menaikan $\mathrm{pH}$ tanah sehingga dapat berpengaruh terhadap aktivitas cacing tanah lebih baik.

\section{KESIMPULAN}

Kesimpulan dari hasil penelitian ini yaitu (1). Pemberian pupuk hayati (Bio max grow) dengan dosis $10 \mathrm{ml} \mathrm{L}^{-1}$ mampu meningkatkan populasi dan biomassa cacing tanah di kedalaman $0-10 \mathrm{~cm}$, dan $10-20 \mathrm{~cm}$ pada umur 86 HST, (2). Pemberian pupuk pelengkap (Plant catalyst) mampu meningkatkan populasi cacing tanah di kedalaman $0-10,10-20$, dan $20-30 \mathrm{~cm}$ dan biomassa cacing tanah di kedalaman $0-10$ dan $10-20$ cm pada umur 86 HST, (3). Terdapat interaksi antara pupuk hayati dan Pupuk Pelengkap terhadap populasi dan biomassa cacing tanah di kedalaman $0-10 \mathrm{~cm}, 10$ $-20 \mathrm{~cm}$ dan $20-30 \mathrm{~cm}$. Tanpa pemberian pupuk hayati, pupuk pelengkap dengan konsentrasi $0,0,5$, 1, dan 1,5 g $\mathrm{L}^{-1}$ dapat meningkatkan populasi cacing tanah, sedangkan pada pemberian pupuk hayati $10 \mathrm{ml} \mathrm{L}^{-1}$, pupuk pelengkap dengan konsentrasi $1 \mathrm{~g} \mathrm{~L}^{-1}$ menghasilkan populasi dan biomassa cacing tanah lebih tinggi dibandingkan konsentrasi pupuk pelengkap lainnya pada umur 86 HST.

\section{DAFTAR PUSTAKA}

Barnes, M dan P. H. Granval.1977. Earthworms as Bio-indicators of Forest Site

Quality. Jurnal Soil Biol Biochem, 29: 323-328.

Buck. C., M. Langmaack, and S. Schrader. 1999. Nutrient Content of Earthworm

Cast Influencedby Different Mulch Types. Eur. J. Soil Biol, 55: 23-30.

Buckman, H.O. dan N.C. Brady. 1982. Ilmu Tanah. Bhratara Karya Aksara.. Jakarta. 64-68 hlm.

PT. Centranusa Insan Cemerlang. 2001. Pupuk Pelengkap Cair. Plant Catalyst 2006. Jakarta.

Rao MB.1994. Molecular and Biotechnologi Aspect of Microbial Proteases. J. microbiol mol Biol. 63(3): 597"635. 
Siddique, J. 2005. Growth and Reproduction Of Earthworm (Eisenia Fetida) In Different Organic Media. J. ofZoology. 37(3), 211 - 214.

Sugiyarto. 2003.Teknik Sampling. Jakarta. PT. Gramedia Pustaka Utama.

Suin, N. M. 1982. Ekologi Fauna tanah. Bumi Aksara. Jakarta.189 hlm.

Tim Plant Catalyst 2006. 2006. Buku Panduan Plant Catalyst 2006. PT. Citra Nusa Insan Cemerlang. Jakarta

Waluyo, L. 1993. Mikrobiologi Lingkungan. Yogyakarta: UMM Press. $80 \mathrm{hlm}$. 